\title{
Morphological categorization of acid-base resistant zones with self-etching primer adhesive systems
}

\author{
Go INOUE ${ }^{1}$, Toru NIKAIDO ${ }^{1}$, Alireza SADR ${ }^{1,2}$ and Junji TAGAMI ${ }^{1,2}$ \\ ${ }^{1}$ Cariology and Operative Dentistry, Department of Restorative Sciences, Graduate School of Medical and Dental Sciences, Tokyo Medical and \\ Dental University, 1-5-45 Yushima, Bunkyo-ku, Tokyo 113-8549, Japan \\ ${ }^{2}$ Global COE Program; International Research Center for Molecular Science in Tooth and Bone Diseases, 1-5-45 Yushima, Bunkyo-ku, Tokyo \\ 113-8549, Japan \\ Corresponding author, Go INOUE; E-mail: inoue.ope@tmd.ac.jp
}

\begin{abstract}
This study investigated the influence of the composition of self-etching primer adhesive systems on the morphology of acid-base resistant zones (ABRZs). One-step self-etching primer systems (Clearfil Tri-S Bond, G-Bond, and One-Up Bond F Plus) and two-step self-etching primer systems (Clearfil SE Bond, Clearfil Protect Bond, UniFil Bond, and Mac Bond II) were used in this study. Each adhesive was applied on prepared dentin disk surfaces, and a resin composite was placed between two dentin disks. All resin-bonded specimens were subjected to acid-base challenge. Observation under a scanning electron microscope (SEM) revealed the creation of an ABRZ adjacent to the hybrid layer for all the self-etch primer adhesive systems, even when non-fluoride releasing adhesives were used. The presence of fluoride in two-step self-etching adhesive significantly increased the thickness of ABRZ created. Results suggested that an ABRZ was created with the use of self-etching primer adhesive systems, but its morphology differed between oneand two-step self-etching primer adhesive systems and was influenced by fluoride release activity.
\end{abstract}

Keywords: Acid-base resistant zone, Self-etching primer, Fluoride-releasing, Super dentin

\section{INTRODUCTION}

In restorative dentistry, long-term durability of resin bonds to dentin is key to the long-term clinical safety and success of dental restorations. Advances in adhesive technology have simplified resin bonding via the development of self-etching primer adhesive systems, which carry these features and benefits: effective bonding to dentin ${ }^{1,2}$, reduced technique sensitivity, reduced procedural steps and hence reduced chairside time. However, these benefits of convenience and time-saving are accompanied by a compromise in bond strength: one-step self-etching primer adhesive systems are more commonly associated with low bond strengths and bond failures than two-step self-etching primer adhesive systems ${ }^{2,3)}$.

Inadequate marginal adaptation of composite restorations, which is associated with compromised bonding integrity, causes micro-gaps to be formed at the interface between restorative materials and cavity wall. These micro-gaps at the interface of restorations allow invasion of fluids and bacteria leading to secondary caries $^{1)}$, which is the most common reason given for the failure and replacement of restorations.

Tsuchiya et al. ${ }^{4)}$ reported that prevention of secondary caries around a restoration was influenced by the physical properties of adhesive materials, quality of hybrid layer, and fluoride release. With the use of self-etch primer adhesive systems, the adhesive resin impregnated the exposed collagen bundles and became entangled with them to create a hybrid layer. A thin

Color figures can be viewed in the online issue, which is available at J-STAGE.

Received Jun 2, 2011: Accepted Nov 29, 2011

doi:10.4012/dmj.2011-132 JOI JST.JSTAGE/dmj/2011-132 layer known as "acid-base resistant zone" (ABRZ) was formed adjacent to the hybrid layer at the adhesivedentin interface after acid-base challenge ${ }^{4)}$. ABRZ could resist against acid challenge, hence giving rise to the ability to resist demineralization and prevent secondary caries development.

ABRZ formation, in terms of morphological and mechanical characteristics, is greatly influenced by adhesive material composition. With a total-etch system such as Single Bond (3M ESPE, MN, USA), the top surface of the hybrid layer was degraded by acid-base challenge and no ABRZ was detected ${ }^{5}$. With one- and two-step self-etching primer adhesive systems, ABRZ was clearly observed adjacent to the hybrid layer ${ }^{5}$.

For improved resistance against secondary caries, fluoride-containing adhesive systems were developed to inhibit the action of secondary caries arising from enamel cracks or microleakage at the tooth-restoration interface. Fluoride-releasing restorative materials are known for their ability to release and recharge fluoride, and for their antibacterial and cariostatic properties. It has also been found that use of fluoride-releasing adhesives caused a thick ABRZ to be formed adjacent to the hybrid layer, hence contributing significantly to secondary caries prevention $^{6}$.

Although a lot remained to be known about ABRZ, it has been clearly shown ${ }^{4-6)}$ that use of self-etching primer adhesive systems resulted in the formation of ABRZ adjacent to the hybrid layer. This implied the secondary caries inhibiting potential of self-etching primer adhesive systems. Using scanning electron microscopy (SEM), the purpose of this study was to investigate the effects of self-etching primer adhesive systems and fluoride 
release on ABRZ morphology.

\section{MATERIALS AND METHODS}

The compositions and manufacturers of the materials used in this study are listed in Table 1.

\section{Human tooth specimens}

Extracted human molars were obtained under a protocol approved by the Ethical Committee at Tokyo Medical and Dental University. Before use, the teeth were cleaned of debris and then stored frozen.

Each tooth was cut into one or two 1.5-mm-thick disks of approximately $1 \mathrm{~cm}$ diameter, parallel to the occlusal surface with a low-speed diamond saw (Isomet, Buehler, Lake Bluff, IL, USA). The obtained dentin disks were ground with wet 600-grit silicon carbide papers under running water. One side of each dentin disk was applied with one of the adhesive systems according to each manufacturer's instructions. A flowable resin composite (Metafil Flo, shade A2, Sun Medical, Moriyama, Japan) was placed between pairs of prepared dentin disks and light-cured for $40 \mathrm{~s}$ from the top and bottom surfaces to make a dentin disk sandwich. After 24-h storage in distilled water, each dentin disk sandwich was sectioned perpendicular to the dentinadhesive interface with a diamond saw. Sectioned specimens were embedded in an epoxy resin (EpoxiCure resin, Buehler, Lake Bluff, IL, USA).

\section{Acid-base challenge}

The exposed surfaces of epoxy resin-embedded specimens were subjected to an acid challenge by being immersed in $100 \mathrm{~mL}$ of a buffered demineralizing solution for 90 min, which contained $2.2 \mathrm{mmol} / \mathrm{L} \mathrm{CaCl}_{2}, 2.2 \mathrm{mmol} / \mathrm{L}$ $\mathrm{NaH}_{2} \mathrm{PO}_{4}$, and $50 \mathrm{mmol} / \mathrm{L}$ acetic acid adjusted to a $\mathrm{pH} 4.5$ to create artificial secondary caries ${ }^{7}$. To remove demineralized dentin collagen fibrils after acid challenge, specimens were immersed in 5\% sodium hypochlorite for $20 \mathrm{~min}$ and then rinsed with running water for $30 \mathrm{~s}$.

\section{SEM observation}

The edges of adhesives could be worn away during specimen polishing ${ }^{8)}$. To prevent wear of the adhesives, a 4-META/MMA-TBB resin (Super-Bond C\&B, Sun Medical, Moriyama, Japan) was applied on the treated surface without prior acid-etching. After curing of the 4-META/MMA-TBB resin, the specimens were sectioned perpendicular to the dentin-adhesive interface, reduced to a thickness of approximately $1 \mathrm{~mm}$, and then polished with diamond pastes (Struers A/S, Ballerup, Denmark) down to $0.25 \mu \mathrm{m}$.

To bring the hybrid layer into sharp relief, the polished surfaces were etched with an argon ion beam

Table 1 Materials used in this study

\begin{tabular}{|c|c|c|}
\hline Material & Composition & Manufacturer \\
\hline \multicolumn{3}{|l|}{ Adhesive System } \\
\hline Clearfil Tri S bond & $\begin{array}{l}\text { Bis-GMA, HEMA, ethanol, MDP, Colloidal silica, dl-Camphorquinone, } \\
\text { Water, PI, CA }\end{array}$ & $\begin{array}{l}\text { Kuraray Medical, } \\
\text { Tokyo, Japan }\end{array}$ \\
\hline G-Bond & $\begin{array}{l}\text { 4-MET, phosphoric ester monomer, UDMA, water, silica filler, PI, } \\
\text { acetone }\end{array}$ & $\begin{array}{l}\text { GC Corp., Tokyo, } \\
\text { Japan }\end{array}$ \\
\hline One-Up Bond F Plus & $\begin{array}{l}\text { A: MAC-10, Bis-MPEPP, Phosphate monomer, MMA } \\
\text { B: HEMA, MMA, Fluoro allumino silicate glass, water, PI }\end{array}$ & $\begin{array}{l}\text { Tokuyama Dental, } \\
\text { Tokyo, Japan }\end{array}$ \\
\hline UniFil Bond & $\begin{array}{l}\text { Primer: HEMA, 4-MET, ethanol, water } \\
\text { Adhesive resin : UDMA, HEMA, TEGDMA, silanated colloidal silica }\end{array}$ & $\begin{array}{l}\text { GC Corp., Tokyo, } \\
\text { Japan }\end{array}$ \\
\hline MacBond II & $\begin{array}{l}\text { Primer A: Phosphate monomer, MAC-10, acetone, PI } \\
\text { Primer B: water, isopropanol } \\
\text { Adhesive: Bis-GMA, TEGDMA, HEMA, MAC-10 }\end{array}$ & $\begin{array}{l}\text { Tokuyama Dental, } \\
\text { Tokyo, Japan }\end{array}$ \\
\hline Clearfil SE Bond & $\begin{array}{l}\text { Primer: MDP, HEMA, water, PI, accelerators, CA } \\
\text { Adhesive: MDP, HEMA, dimethacrylates, PI, CA, microfiller }\end{array}$ & $\begin{array}{l}\text { Kuraray Medical, } \\
\text { Tokyo, Japan }\end{array}$ \\
\hline Clearfil Protect Bond & $\begin{array}{l}\text { Primer: MDPB, MDP, HEMA, MFM, PI, water } \\
\text { Adhesive: MDP, HEMA, MFM, PI, microfiller, NaF }\end{array}$ & $\begin{array}{l}\text { Kuraray Medical, } \\
\text { Tokyo, Japan }\end{array}$ \\
\hline \multicolumn{3}{|l|}{ Restorative Material } \\
\hline Metafil Flo & $\begin{array}{l}\text { 2,2-Bis[4-(methacryloxy-polyethoxy)phenyl]propane, bifunctional } \\
\text { methacrylate monomers, silica, 3-(trimethoxysilyl)propyl methacrylate }\end{array}$ & $\begin{array}{l}\text { Sun Medical, } \\
\text { Moriyama, Japan }\end{array}$ \\
\hline
\end{tabular}

Bis-GMA: 2,2-bis[4-(2-hydroxy-3-methacryloxypropoxy)phenyl]propane; Bis-MPEPP: 2,2-bis[(4-methacryloxy polyethoxy) phenyl]propane; CA: Catalyst; HEMA: 2-hydroxyethyl methacrylate; MAC-10: 10-methacryloyloxy dideca methylene malonate; MDP: 10-methacryloxydecyl dihydrogen phosphate; PI: Photoinitiator; MDPB: 12-methacryloyloxydodecylpyridinium bromide; MFM: Multifunctional methacrylate; NaF: Sodium fluoride; TEGDMA: Triethylene glycol dimethacrylate; UDMA: Urethane dimethacrylate resin; 4-MET: 4-methacryloxyethyltrimellitate 
(EIS-IE, Elionix, Tokyo, Japan) directed perpendicular to the polished surface for $7 \mathrm{~min}$ under these operating conditions: $1 \mathrm{kV}$ of acceleration voltage and $0.2 \mathrm{~mA} / \mathrm{cm}^{2}$ of ion current density ${ }^{9}$. The specimens were gold sputtercoated, and morphological changes to the dentinadhesive interface due to acid-base challenge were observed using a SEM (JSM-5310LV, JEOL, Tokyo, Japan).

\section{RESULTS}

For all the specimens, the 4-META/MMA-TBB resin protective layer successfully prevented the wear and damage of adhesives and resin composites. Figures 1-7 show the ultrastructures of the dentin-adhesive interfaces after acid-base challenge. The outer lesion, which was the dentin surface demineralized after acid-base challenge, was observed for all the self-etch primer adhesive systems. Depth of the outer lesion ranged from $5 \mu \mathrm{m}$ to $15 \mu \mathrm{m}$, and there were no differences in the morphological appearance among the adhesive systems.

One-step self-etching primer adhesive systems

Under the magnifications used in this study, it was difficult to detect the hybrid layer. The ABRZ adjacent to the hybrid layer, ranging from less than $1 \mu \mathrm{m}$ to more than $1 \mu \mathrm{m}$, was clearly observed for all the one-step self-etching primer adhesive systems (Figs. 1-3).

For Clearfil Tri S Bond, dentin located next to the ABRZ was more eroded than in other areas of the dentin surface (Fig. 1). Conversely for One-Up Bond F Plus, the top part of ABRZ sloped downwards toward the bottom of the outer lesion (Fig. 3).
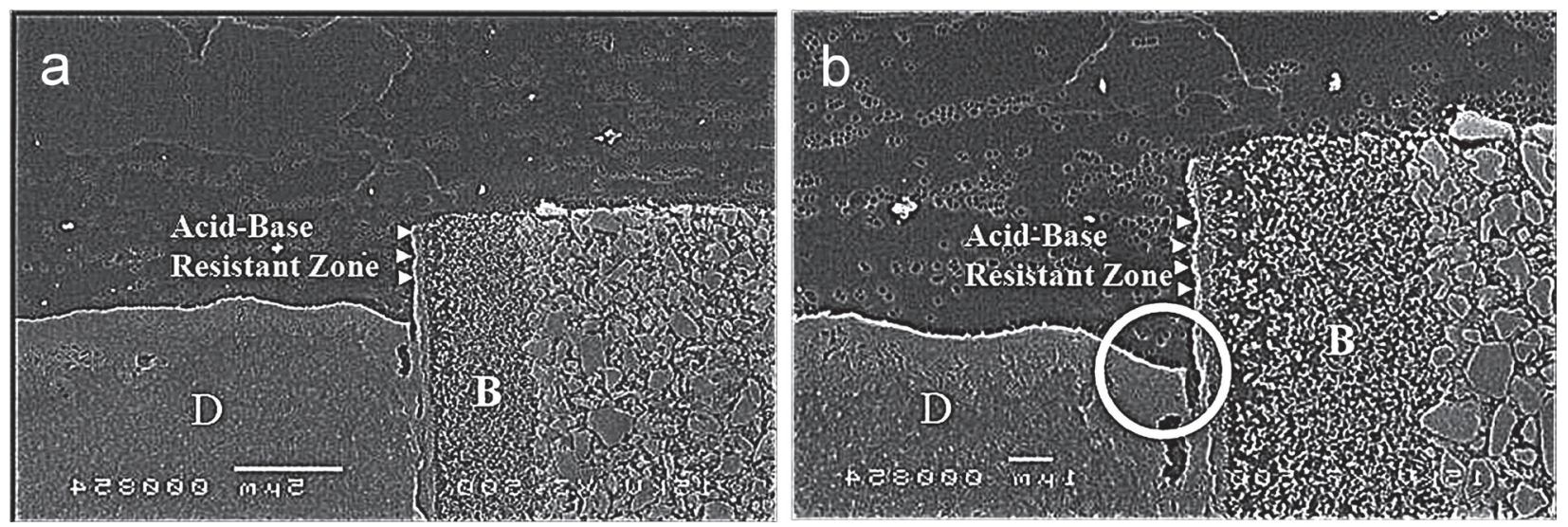

Fig. 1 Ultrastructure of adhesive-dentin interface of Clearfil Tri S Bond under different magnifications:

(a) Outer lesion of approximately $5 \mu \mathrm{m}$ thickness was observed under 3,500 magnification. ABRZ (white arrowheads) was clearly detected beneath dentin.

(b) ABRZ of less than $1 \mu \mathrm{m}$ thickness was observed under 7,500 magnification. There was erosion around the bottom of ABRZ (circle).
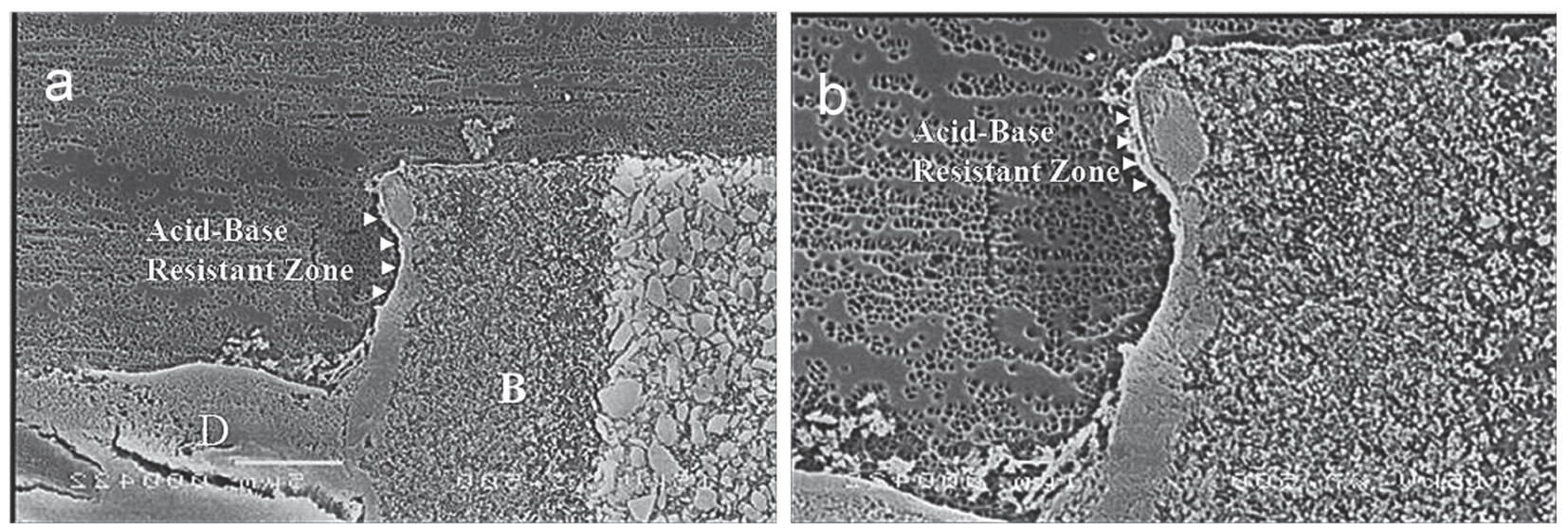

Fig. 2 Ultrastructure of adhesive-dentin interface of G-Bond under different magnifications:

(a) Outer lesion of approximately $7 \mu \mathrm{m}$ thickness was observed under 3,500 magnification. ABRZ (white arrowheads) was clearly detected beneath dentin.

(b) ABRZ of approximately $1 \mu \mathrm{m}$ thickness was observed under 7,500 magnification. 

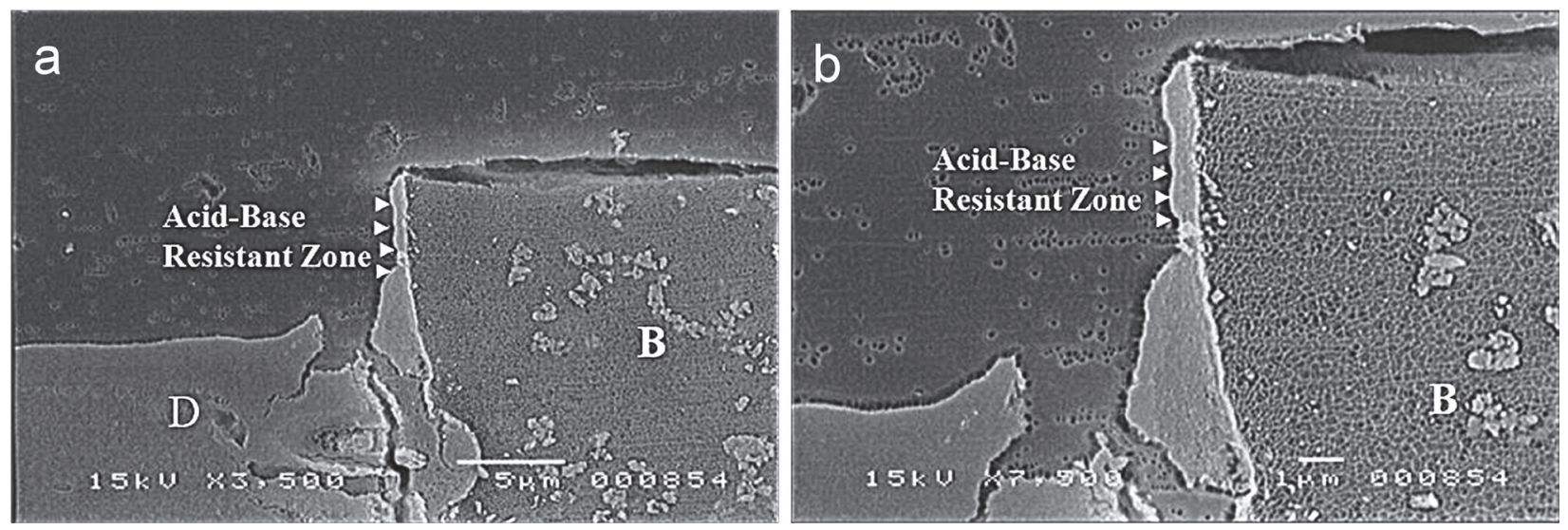

Fig. 3 Ultrastructure of adhesive-dentin interface of One-Up Bond F Plus under different magnifications:

(a) Outer lesion of approximately $7 \mu \mathrm{m}$ thickness, like G-Bond, was observed under 3,500 magnification. A thick ABRZ (white arrowheads) was clearly detected beneath dentin.

(b) ABRZ of thickness exceeding $1 \mu \mathrm{m}$ was observed under 7,500 magnification.
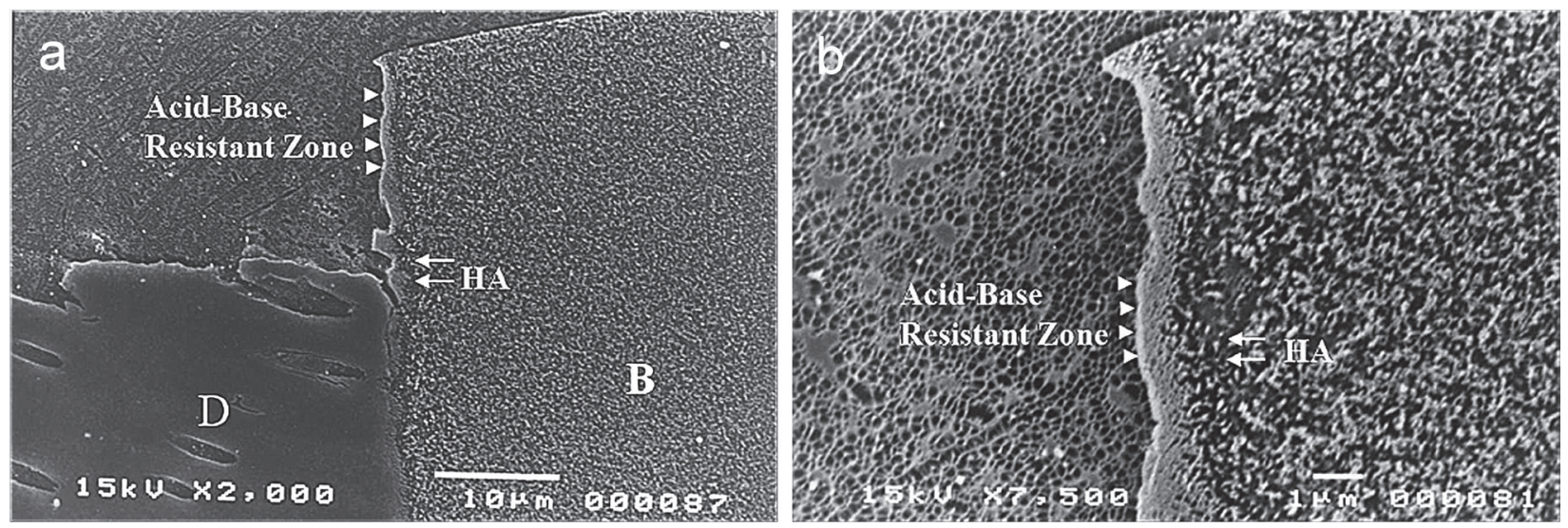

Fig. 4 Ultrastructure of adhesive-dentin interface of Clearfil SE Bond under different magnifications:

(a) Outer lesion of approximately $15 \mu \mathrm{m}$ thickness was observed under 2,000 magnification. ABRZ (white arrowheads) was clearly detected beneath dentin.

(b) ABRZ of less than $1 \mu \mathrm{m}$ thickness was observed under 7,500 magnification.

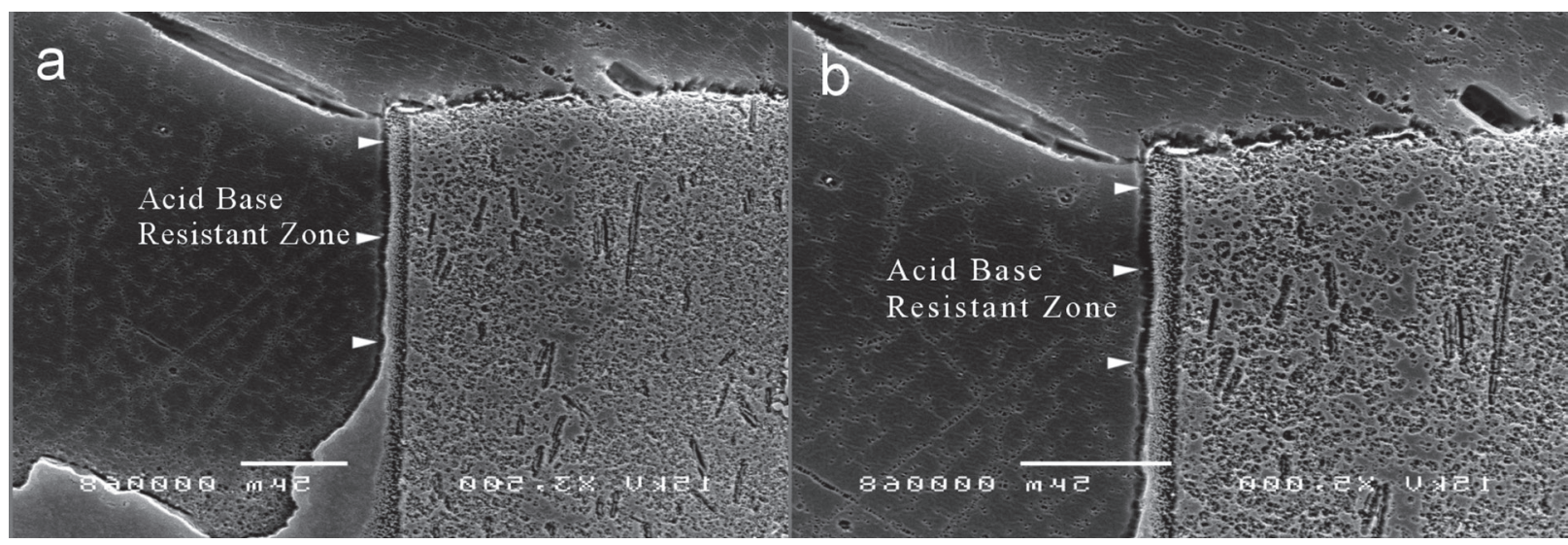

Fig. 5 Ultrastructure of adhesive-dentin interface of Clearfil Protect Bond under different magnifications:

(a) Outer lesion of approximately $12 \mu \mathrm{m}$ thickness was observed under 3,500 magnification. ABRZ (white arrowheads) was clearly detected beneath dentin. Top part of ABRZ sloped downwards toward the bottom of outer lesion.

(b) ABRZ of approximately $1 \mu \mathrm{m}$ thickness was observed under 7,500 magnification. 

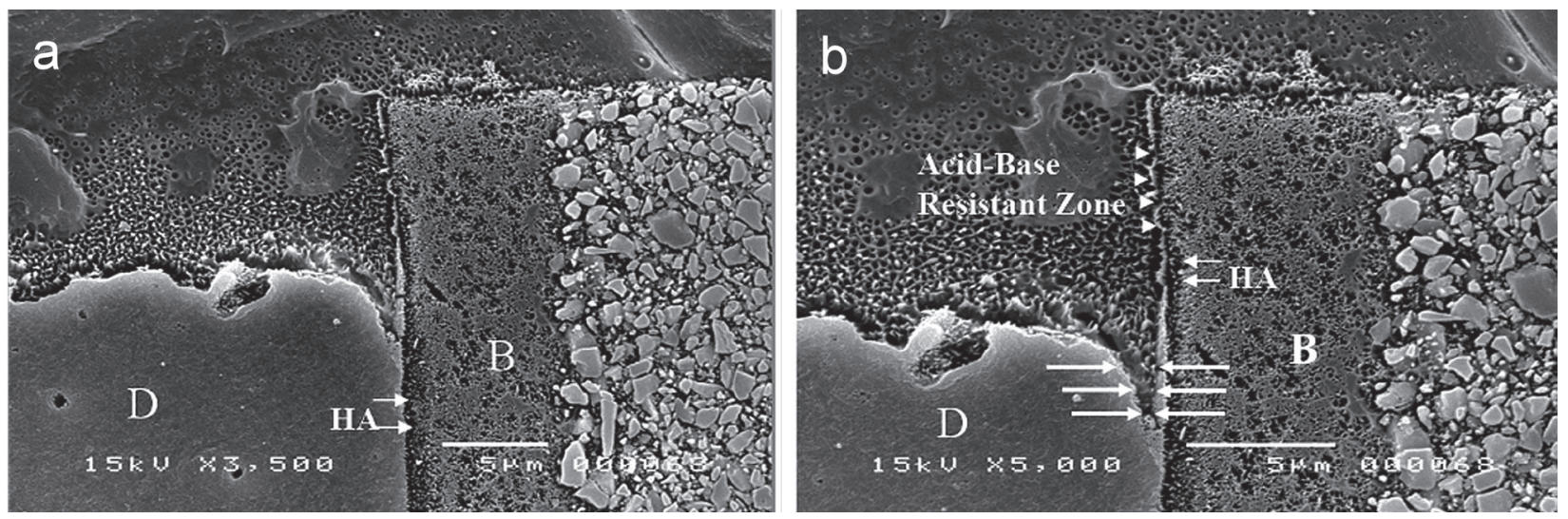

Fig. 6 Ultrastructure of adhesive-dentin interface of UniFil Bond under different magnifications:

(a) Outer lesion of approximately $8 \mu \mathrm{m}$ thickness was observed under 3,500 magnification. A very thin ABRZ was clearly detected beneath dentin.

(b) ABRZ (white arrowheads) of less than $0.5 \mu \mathrm{m}$ thickness was observed under 5,000 magnification. There was erosion around the bottom of ABRZ (white arrows).
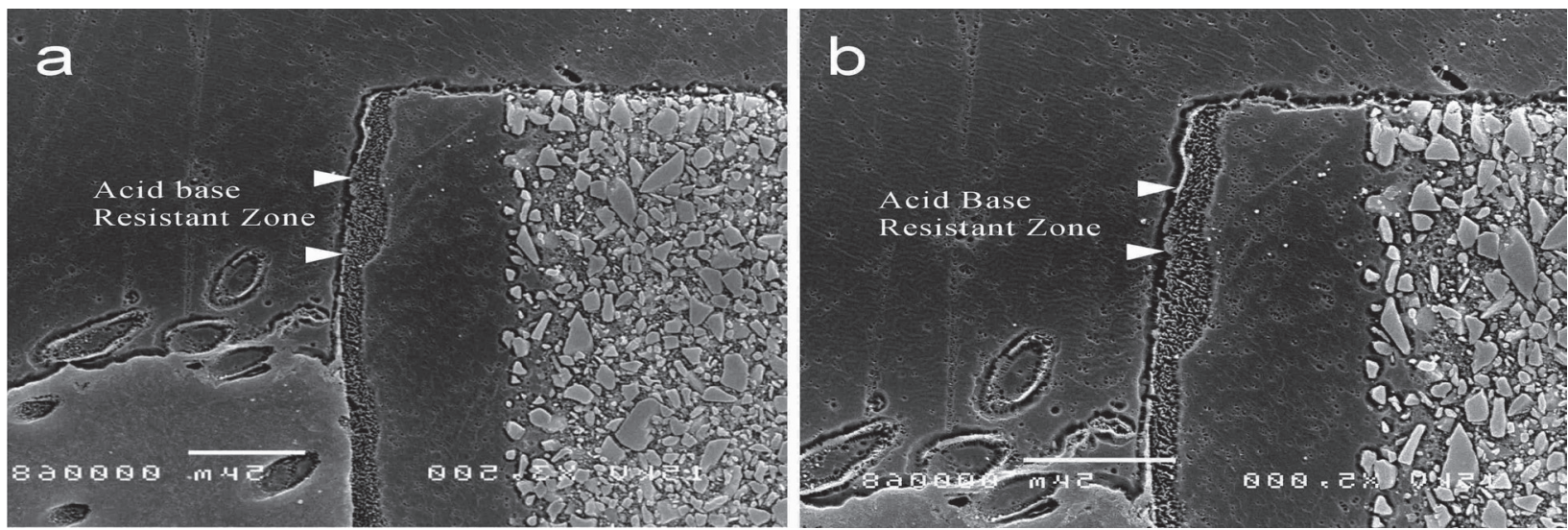

Fig. 7 Ultrastructure of adhesive-dentin interface of Mac Bond II under different magnifications:

(a) Outer lesion of approximately $12 \mu \mathrm{m}$ thickness was observed under 3,500 magnification. A thin ABRZ (white arrowheads) was clearly detected beneath dentin.

(b) ABRZ of less than $0.5 \mu \mathrm{m}$ thickness was observed under 5,000 magnification.

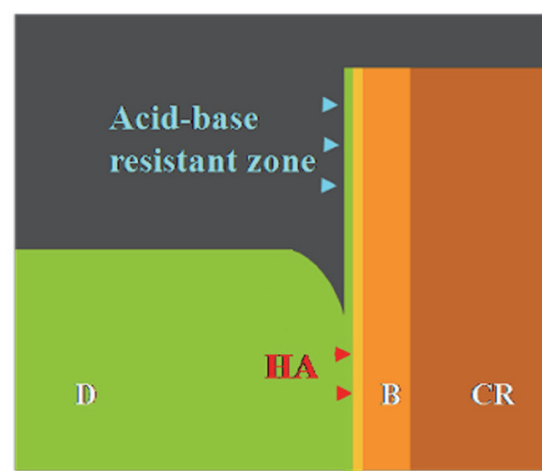

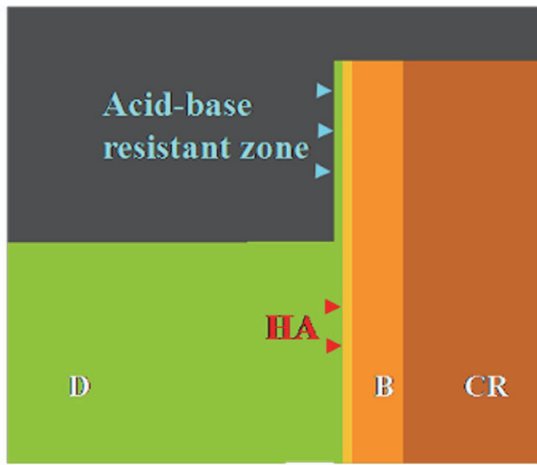

\section{G Bond \\ Clearfil SE Bond MacBond II}

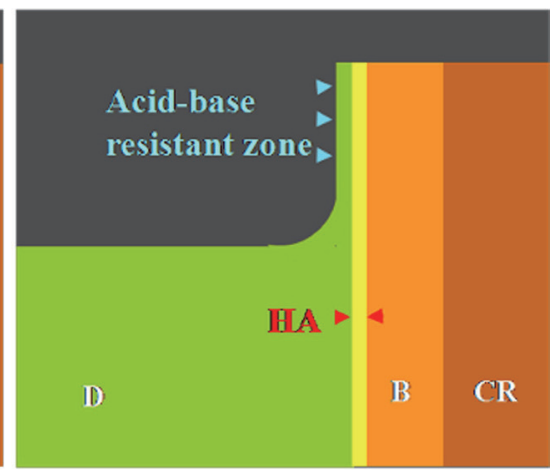

OBF-Plus

Clearfil Protect Bond

Fig. 8 Schematic illustration of the different categories of the characterized morphologies of ABRZ. 
Two-step self-etching primer adhesive systems

For Clearfil SE Bond, a hybrid layer (HA) of approximately $1 \mu \mathrm{m}$ was detected after argon ion etching. ABRZ, which could be clearly seen, was approximately $1 \mu \mathrm{m}$ thick (Fig. 4).

For Clearfil Protect Bond, approximately $1 \mu \mathrm{m}$ of HA was detected. ABRZ was approximately $1 \mu \mathrm{m}$ thick and the top part of ABRZ sloped downwards toward the bottom of the outer lesion (Fig. 5).

For UniFil Bond, only a very thin ABRZ of less than $0.5 \mu \mathrm{m}$ was observed. Like Clearfil Tri S Bond, dentin located next to the ABRZ was more eroded more than in other areas of the dentin surface (Fig. 6).

For Mac Bond II, HA of more than $1 \mu \mathrm{m}$ was detected. However, a very thin ABRZ of less than $0.5 \mu \mathrm{m}$ was observed and it discontinued as in the case of UniFil Bond (Fig. 7).

\section{DISCUSSION}

At the resin-dentin adhesive interface, the hybrid layer was defined by Nakabayashi et al.9) as the structure formed in hard dental tissues by demineralization of the surface and subsurface, followed by infiltration of monomers and subsequent polymerization. Hybrid layer formation enhances resin-dentin adhesion, and good interfacial bonding is a decidedly important factor to delivering an optimal long-term clinical outcome for dental restorations. For this reason, numerous studies have employed electron microscopy tools, such as scanning electron microscopy (SEM) and transmission electron microscopy (TEM), to gain more insight into the morphological and mechanical characteristics of the resin-dentin interdiffusion zone: extent and uniformity of adhesive resin penetration into tooth substrates, appearance, length, and continuity of resin tags, quality of hybridization within the interdiffusion zone, and thickness of the hybrid layer ${ }^{9-21)}$.

Reports on hybrid layer thickness varied, with values ranging from less than $1 \mu \mathrm{m}$ to approximately 13 $\mu \mathrm{m}$ in sound dentin ${ }^{9,19-21)}$. Lower values were reported for sclerotic dentin ${ }^{18)}$, while higher values for demineralized dentine $\mathrm{e}^{22,23)}$. Amongst the factors that affected hybrid layer formation, it seemed that the kind of adhesive system and application technique had a substantial influence on the extent and structure of the hybrid layer created. Studies have shown that two-step, self-etch adhesives produced clearly defined hybrid layers and resin tags with more lateral branches than one-step, self-etch adhesives.

In our previous study ${ }^{8)}$, ABRZ was identified as part of the hybrid layer. Higher microhardness of the cariesaffected demineralized dentin $2 \mu \mathrm{m}$ beneath the hybrid layer, created after the use of two-step self-etching primer adhesive system, supported the theory that ABRZ was composed of penetrated resin monomer and dentin partially demineralized by self-etching primer ${ }^{8}$. Watanabe et $a l .^{24)}$ reported that after mild acidic treatment with a self-etching primer adhesive system, TEM observation of the resin-dentin interface revealed hydroxyapatite particles being wrapped with resin monomer remaining beneath the hybrid layer. In another report by Nikaido et al. ${ }^{25)}$ whereby two one-step self-etching primer adhesive systems were used, SEM observation of the resin-dentin interface after acid-base challenge revealed that a hybrid layer less than $1 \mu \mathrm{m}$ thick was created. An ABRZ was formed adjacent to the hybrid layer for both adhesives, and TEM observation also indicated that these ABRZs contained mineral components $^{25)}$. Yoshida et $a l{ }^{26)}$ also echoed that since mild self-etch adhesives demineralized dentin only partially, some hydroxyapatite crystals remained attached to the collagen fibrils within a submicron hybrid layer. These residual hydroxyapatite crystals could serve as receptors for chemical interaction with functional monomers in self-etch adhesive systems ${ }^{27)}$. This meant that it was probable that differences in the functional monomers present in each adhesive system could affect the formation and morphology of ABRZs created.

Nikaido et al. ${ }^{25)}$ demonstrated that the thickness of ABRZs formed was material-dependent. In other words, the morphology of ABRZs created depended on the kind of adhesive system used, especially whether one-step or two-step self-etch primer adhesive systems were used. Figure 8 is a schematic illustration of the ultrastructures of the adhesive-dentin interfaces of one- and two-step self-etching primer adhesive systems after acid-base challenge in this study. Morphological characteristics of the ABRZs created were categorized into three pattern groups: (a) Clearfil Tri S Bond and UniFil Bond; (b) G-Bond, Clearfil SE Bond, and Mac Bond II; and (c) One-Up Bond F Plus and Clearfil Protect Bond. An ABRZ was clearly detected for all self-etch primer adhesive systems used in this study; nonetheless, morphological differences existed among the three pattern groups.

For Clearfil Tri S Bond and UniFil Bond, an eroded dentin area next to ABRZ was observed. This was probably because mild acid etching did not allow the resin monomers to penetrate the demineralized dentin fully and thoroughly, causing nanospace to remain beneath their ABRZs. For G-Bond, Clearfil SE Bond, and Mac Bond II, no erosion was observed. Among these three adhesive systems, the ABRZ created with Mac Bond II was thinner than those of G-Bond and Clearfil $\mathrm{SE}$ Bond. It was suggested that the monomer of Mac Bond II did not penetrate fully and cure completely as did the resin monomers of G-Bond and Clearfil SE Bond. For One-Up Bond F Plus and Clearfil Protect Bond, ABRZs with a downward slope were created probably due to fluoride release. In our previous study, we found that fluoride release from adhesives was a key factor to creating thick $\mathrm{ABRZ}_{\mathrm{s}}{ }^{27)}$. Nonetheless, an ABRZ was created with both fluoride-free and fluoride-releasing self-etch adhesive systems and that formation of ABRZs with a downward slope was material-dependent ${ }^{27)}$.

The ABRZ is different from the inhibition zone which is formed due to fluoride release. ABRZs were formed despite adhesives being fluoride-free. According 
to Nikaido et $a l .{ }^{25)}$, application of one-step self-etching adhesive systems created an ABRZ at the underlying dentin, which reinforced normal dentin against dental caries. This zone was named "Super Dentin". Formation of "Super Dentin" is a new approach in caries prevention $^{25)}$. For ABRZs, their formation should be related not only to the amount of fluoride released from a fluoride-containing adhesive, but also to the ability of adhesive monomers to infiltrate into the demineralized dentin.

\section{CONCLUSIONS}

Within the limitations of this study, the following conclusions were drawn:

1. ABRZ is composed of a mixture of penetrated resin monomer and dentin partially demineralized by self-etching primer, suggesting that ABRZ is part of the hybrid layer according to the latter's definition $^{9)}$.

2. The existence of ABRZ suggested that resin monomers could penetrate into dentin deeper than previously reported.

\section{REFERENCES}

1) Burrow MF, Kitasako Y, Thomas CD, Tagami J. Comparison of enamel and dentin microshear bond strengths of a two-step self-etching priming system with five all-in-one systems. Oper Dent 2008; 33: 456-460.

2) Knobloch LA, Gailey D, Azer S, Johnston WM, Clelland N, Kerby RE. Bond strengths of one- and two-step self-etch adhesive systems. J Prosthet Dent 2007; 97: 216-222.

3) Senawongse P, Sattabanasuk V, Shimada Y, Otsuki M, Tagami J. Bond strengths of current adhesive systems on intact and ground enamel. J Esthet Restor Dent 2004; 16: 107-116.

4) Tsuchiya S, Nikaido T, Sonoda H, Foxton RM, Tagami J. Ultrastructure of the dentin-adhesive interface after acid-base challenge. J Adhes Dent 2004; 6: 183-190.

5) Inoue G, Nikaido T, Foxton RM, Tagami J. The acid-base resistant zone in three dentin bonding systems. Dent Mater J 2009; 28: 717-721.

6) Shinohara MS, Yamauti M, Inoue G, Nikaido T, Tagami J, Giannini M, de Goes MF. Evaluation of antibacterial and fluoride-releasing adhesive system on dentin-microtensile bond strength and acid-base challenge. Dent Mater J 2006; 25: 545-552.

7) Wefel JS, Heilman JR, Jordan TH. Comparisons of in vitro root caries models. Caries Res 1995; 29: 204-209.

8) Inoue G, Tsuchiya S, Nikaido T, Foxton RM, Tagami J. Morphological and mechanical characterization of the acid-base resistant zone at the adhesive-dentin interface of intact and caries-affected dentin. Oper Dent 2006; 31: 466-472.

9) Nakabayashi N, Kojima K, Masuhara E. The promotion of adhesion by the infiltration of monomers into tooth substrates. J Biomed Mater Res 1982; 16: 265-273.

10) Van Meerbeek B, Dhem A, Goret-Nicaise M, Braem M,
Lambrechts P, Vanherle G. Comparative SEM and TEM examination of the ultrastructure of the resin-dentin interdiffusion zone. J Dent Res 1993; 72: 495-501.

11) Shimada $Y$, Harnirattisai C, Inokoshi S, Burrow MF, Takatsu T. In vivo adhesive interface between resin and dentin. Oper Dent 1995; 20: 204-210.

12) Carvalho RM, Yoshiyama M, Pashley EL, Pashley DH. In vitro study on the dimensional changes of human dentine after demineralization. Arch Oral Biol 1996; 41: 369-377.

13) Raspanti M, Alessandrini A, Gobbi P, Ruggeri A. Collagen fibril surface: TMAFM, FEG-SEM and freeze-etching observations. Microsc Res Tech 1996; 35: 87-93.

14) Cagidiaco MC, Ferrari M, Vichi A, Davidson CL. Mapping of tubule and intertubule surface areas available for bonding in Class V and Class II preparations. J Dent 1997; 25: 379-389.

15) Ferrari M, Cagidiaco MC, Kugel G, Davidson CL. Dentin infiltration by three adhesive systems in clinical and laboratory conditions. Am J Dent 1996; 9: 240-244.

16) Ferrari M, Mannocci F, Vichi A, Davidson CL. Effect of two etching times on the sealing ability of Clearfil Liner Bond 2 in Class V restorations. Am J Dent 1997; 10: 66-70.

17) Breschi L, Perdigao J, Lopes MM, Gobbi P, Mazzotti G. Morphological study of resin-dentin bonding with TEM and in-lens FESEM. Am J Dent 2003; 16: 267-274.

18) Kwong SM, Tay FR, Yip HK, Kei LH, Pashley DH. An ultrastructural study of the application of dentine adhesives to acid-conditioned sclerotic dentine. J Dent 2000; 28: 515-528.

19) Van Meerbeek B, Conn LJ Jr, Duke ES, Eick JD, Robinson SJ, Guerrero D. Correlative transmission electron microscopy examination of nondemineralized and demineralized resin-dentin interfaces formed by two dentin adhesive systems. J Dent Res 1996; 75: 879-888.

20) Sakoolnamarka R, Burrow MF, Tyas MJ. Interfacial micromorphology of three adhesive systems created in cariesaffected dentin. Am J Dent 2003; 16: 202-206.

21) Wang Y, Spencer P. Effect of acid etching time and technique on interfacial characteristics of adhesive-dentin bond using differential staining. Eur J Oral Sci 2004; 112: 293-299.

22) Abu-Hanna A, Gordan VV, Mjor I. The effect of variation in etching times on dentin bonding. Gen Dent 2004; 52: 28-33.

23) Wang Y, Spencer P, Walker MP. Chemical profile of adhesive/ caries-affected dentin interfaces using Raman microspectroscopy. J Biomed Mater Res A 2007; 81: 279-286.

24) Watanabe I, Takarada K, Nakabayashi N. Adhesion of 4-META/MMA-TBB resin to dentin pretreated with phosphoric acid. J J Dent Mater 1991; 10: 671-677.

25) Nikaido $T$, Weerasinghe DD, Waidyasekera $K$, Inoue $G$, Foxton RM, Tagami J. Assessment of the nanostructure of acid-base resistant zone by the application of all-in-one adhesive systems: Super dentin formation. Biomed Mater Eng 2009; 19: 163-171.

26) Yoshida Y, Nagakane K, Fukuda R, Nakayama Y, Okazaki M, Shintani H, Inoue S, Tagawa Y, Suzuki K, De Munck J, Van Meerbeek B. Comparative study on adhesive performance of functional monomers. J Dent Res 2004; 83: 454-458.

27) Iida Y, Nikaido T, Kitayama S, Takagaki T, Inoue G, Ikeda M, Foxton RM, Tagami J. Evaluation of dentin bonding performance and acid-base resistance of the interface of two-step self-etching adhesive systems. Dent Mater J 2009; 28: $493-500$. 